\title{
THE TARSAL AND ANTENNAL CHARACTERS OF PSOCIDAE.
}

\author{
BY HERMANN AUGUST HAgEN, CAMBridge, MASS.
}

[Reprint from Entom. mo. mag., June I882, v. I9, p. I2-I3.]

By a mere chance I see that a statement recently published by me concerning the tarsal structure of psocidae confirms, in a most satisfactory manner, that made by Prof. Westwood in 1857 (Proc. Ent. soc. Lond., series 2, vol. iv, pp. 63, 64) regarding certain coleoptera.

Being occupied with the atropina, I was astonished to find that the young forms have only two-jointed tarsi (instead of three-jointed, as is found in the imago), but the last joint, internally, in the middle, shows a more or less visible division, where the 3 rd joint (the median) will be formed, and just below it are one or two small bristles. I have observed this in $A$ [tropos] divinatoria (reared by myself), succinica, and oleagina, and also in Hyperetes tessellatus. So long as the young have only two-jointed tarsi, the antennae have also less joints. Thus, in $A$. divinato- ria the latter have only 12 instead of the 15 of the imago; in Hyperetes the proportions are 13 to 23 . But, although the third (middle) joint of the tarsi is produced by a division of the apical, it is just the contrary with the antennae. In these the two thick basal joints, and the apical joint are not divided; but in some species all the intermediate joints are so. Hyperetes is in the latter case, all the ro intermediate joints being divided in the imago, as I can show from preparations. It is a remarkable fact that the mysterious Hyperetes shows, in its earlier stages, precisely the normal number (r3) of joints for the psocidae. I am not prepared to give an opinion as to this genus. Other genera, such as Caecilius, commonly considered to have only two-jointed tarsi, possess a small aborted third joint, just as occurs in many coleoptera.

Cambridge, Mass., ist April, I882.
The Chigoe in Africa.-- It is stated in Burton and Cameron's "To the Gold Coast for Gold" that the chigoe (Pulex penetrans) has been recently introduced and has spread all over the West African seaboard and far into the interior. At the time of Captain Burton's first visit (I862) it was unknown on the west coast; but now it ranks with the indigenous red, white and black ants, centipedes, scorpions, venomous spiders and flies of the tzetze group, as among the chief plagues of that region.-Amer. naturalist, June I 883, v. I7, p. 664 . 

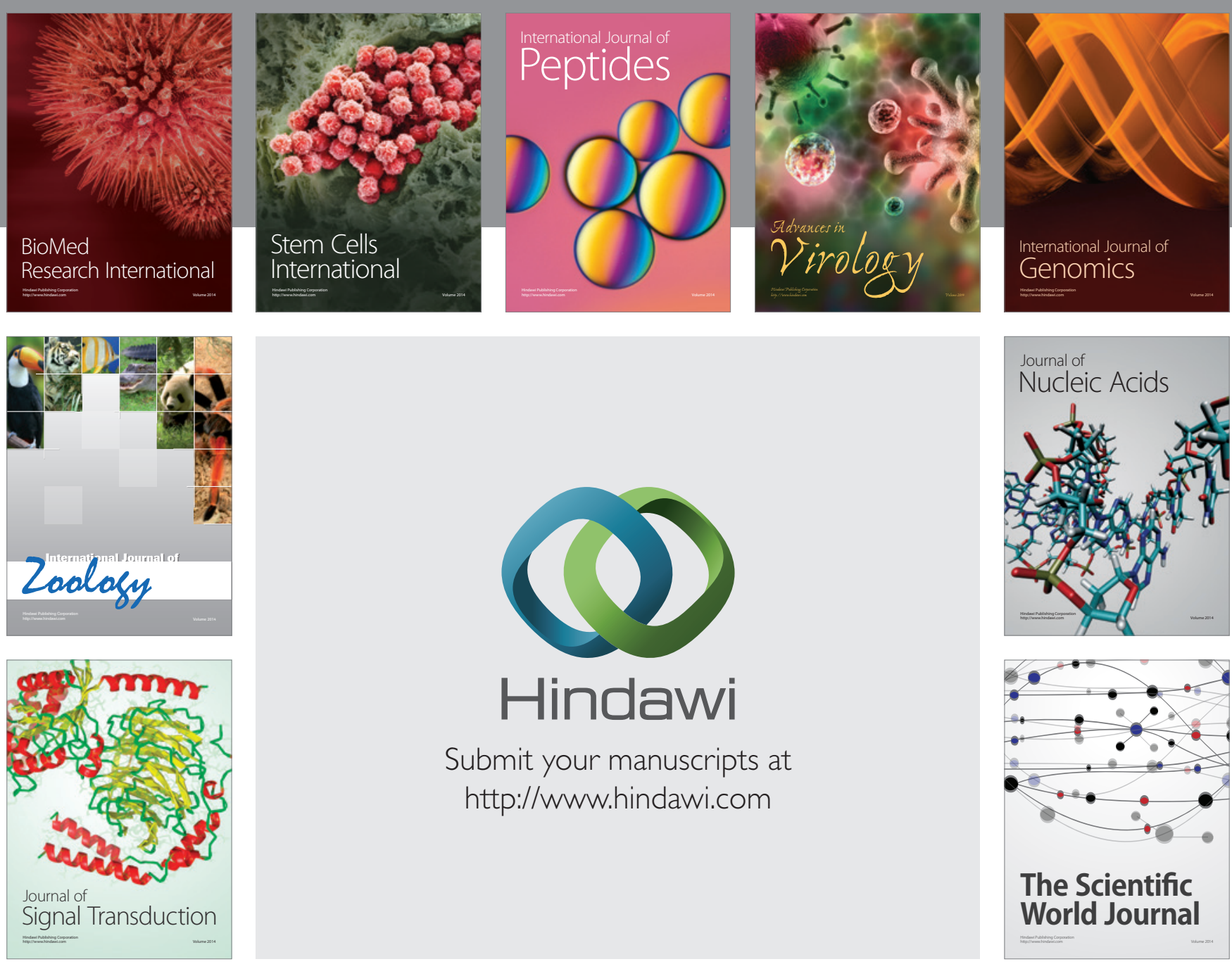

Submit your manuscripts at

http://www.hindawi.com
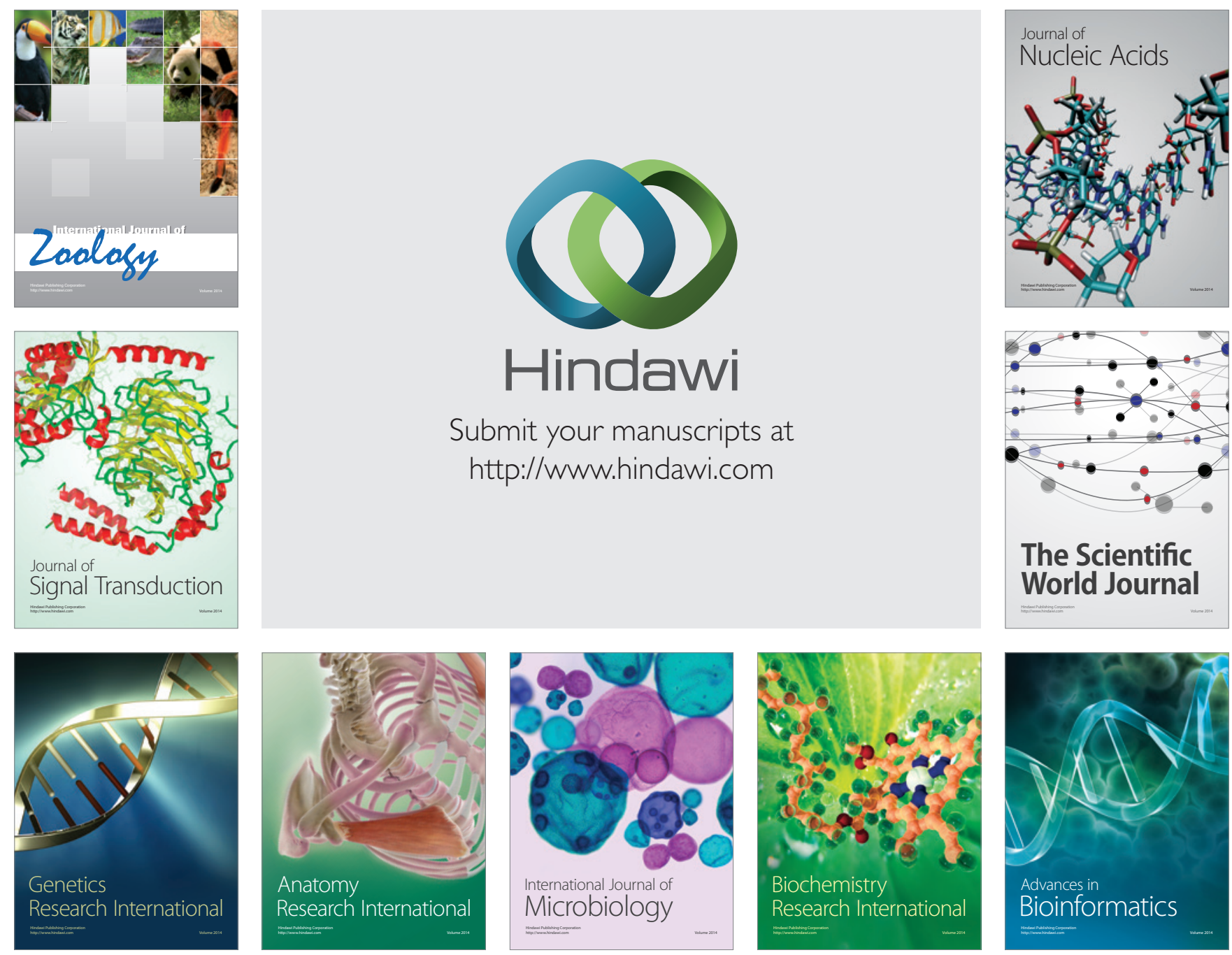

The Scientific World Journal
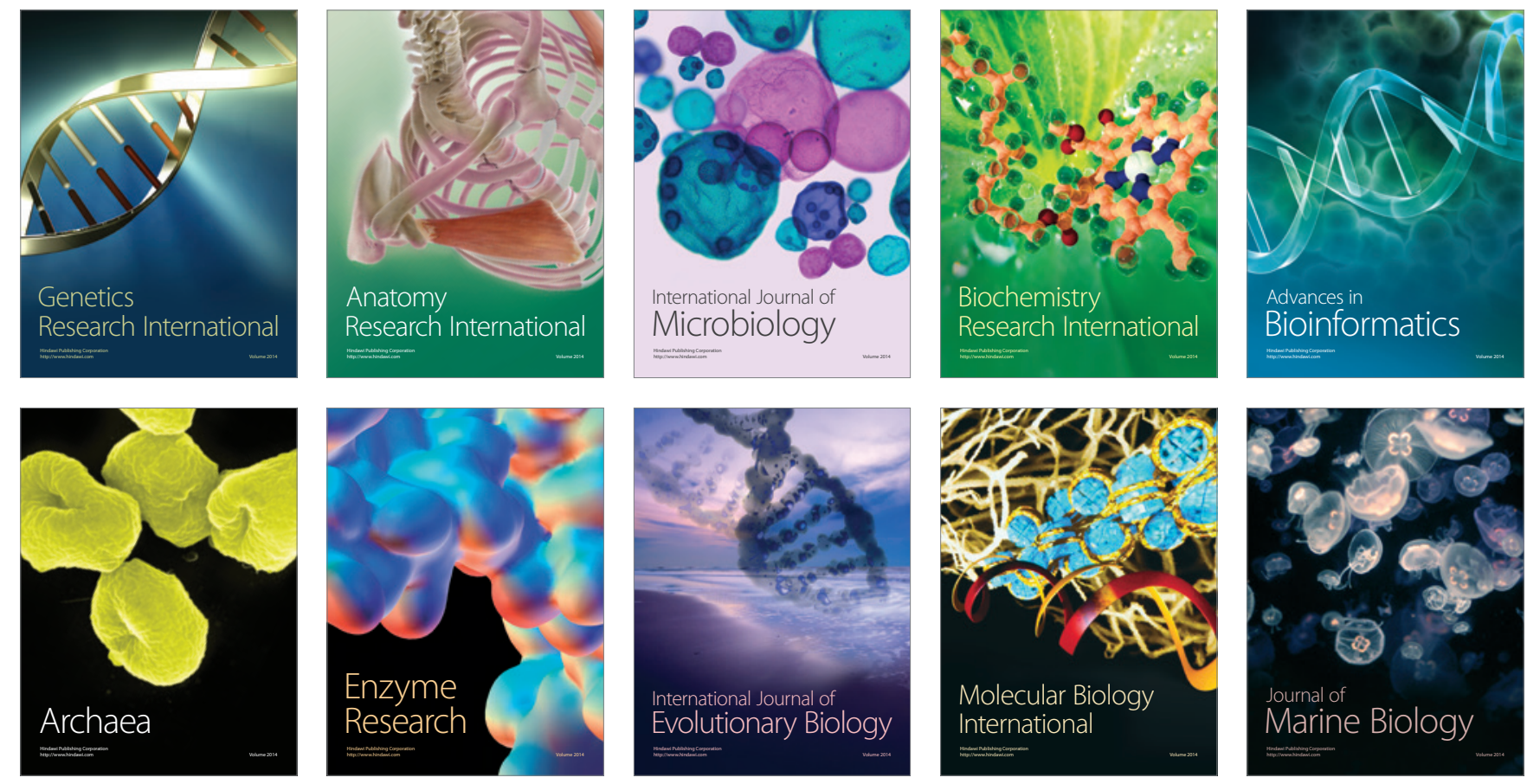